\title{
Fulminant hepatic failure in nephrotic syndrome related to withdrawal of immunosuppressive therapy
}

\author{
James K. Onwubalili \\ Department of Medicine, University of Nigeria Teaching Hospital, P.M.B. 01129, Enugu, Nigeria.
}

\begin{abstract}
Summary: Two patients with nephrotic syndrome developed fatal fulminant hepatitis B following withdrawal of prednisolone or cyclophosphamide. Immunosuppressive therapy probably enhanced hepatitis B virus (HBV) replication and widespread infection of hepatocytes; its withdrawal permitted a return of immune competence resulting in massive destruction of infected hepatocytes. Prior screening of all patients for hepatitis B surface antigen, gradual withdrawal of immunosuppressive drugs with careful monitoring, and prompt intervention with corticosteroids at the first clinical or biochemical signs of liver cell damage may prevent this complication.
\end{abstract}

\section{Introduction}

The prevalence of hepatitis B carriage in reported series of patients with nephrotic syndrome has ranged from 0 to $50 \%,{ }^{1-4}$ the higher figures coming from tropical African countries where both conditions are more common. ${ }^{5,6}$ Immunosuppressive drugs have been used to treat nephrotic syndrome for over 36 years $^{7}$ although it is doubtful that they provide benefit for patients with other than minimal change or autoimmune nephritis. One severe complication which may follow abrupt withdrawal of immunosuppression in hepatitis B surface antigen (HbsAg)-positive patients is massive hepatic necrosis. This complication has been reported in patients with some neoplastic diseases ${ }^{8-10}$ and in a renal transplant recipient ${ }^{11}$ but to my knowledge, not in the nephrotic syndrome.

I report two patients with nephrotic syndrome in whom fulminant acute hepatitis B was apparently precipitated by the withdrawal of immunosuppressive therapy.

\section{Case reports}

Case 1

A 15 year old boy was admitted in September 1985, with nephrotic syndrome and a left inguinal hernia, both of 3 months duration. Examination revealed pallor, anasarca, abdominal tenderness, hepatomegaly and splenomegaly. His blood pressure (BP)

Correspondence: J.K. Onwubalili M.B., B.S., M.D., M.R.C.P.(UK)

Accepted: 23 September 1987 was $120 / 80 \mathrm{~mm} \mathrm{Hg}$. His haemoglobin $(\mathrm{Hb})$ concentration was $8.4 \mathrm{~g} / \mathrm{dl}$, leucocyte count $8.6 \times 10^{9} / 1$ and platelet count $115 \times 10^{9} / 1$. Blood films, serum electrolytes, urea, creatinine, aspartate aminotransferase (AST), bilirubin, blood sugar, electrocardiogram, chest X-ray and $\mathrm{Hb}$ electrophoresis were normal. Serum total protein was $2.4 \mathrm{~g} / \mathrm{dl}$ (normal 6-8), albumin $0.8 \mathrm{~g} / \mathrm{dl}$ (normal 3.54.5 ), globulin $1.6 \mathrm{~g} / \mathrm{dl}$ (normal $2.5-3.5$ ), cholesterol $10.5 \mathrm{mmol} / 1$ (normal 3.9-7.8), creatinine clearance $90 \mathrm{ml} / \mathrm{min}$ and 24 hour urine protein $7.2 \mathrm{~g}$. Culture of ascitic fluid grew Streptococcus pneumoniae. Light microscopic examination of a renal biopsy suggested a minimal change lesion. He could not afford the cost of an HbsAg test which was only commercially available at the time.

$\mathrm{He}$ was treated with benzylpenicillin, $80 \mathrm{~g}$ protein $/ 2 \mathrm{~g}$ salt diet, frusemide and spironolactone. Peritonitis gradually settled and diuresis was established. Oral prednisolone, $50 \mathrm{mg}$ /day was then given for 4 weeks, with complete remission of oedema and proteinuria, and subsequently tapered over 2 weeks.

Sixteen days after prednisolone withdrawal, while he awaited herniorrhaphy, he developed malaise, anorexia, nausea, jaundice, increased tender hepatomegaly (to $6 \mathrm{~cm}$ ) and bile in the urine. Serum bilirubin had increased to $85 \mu \mathrm{mol} / 1$ (normal 3-17), AST to $1350 \mathrm{IU} / 1$ (normal 5-35), and prothrombin time was prolonged by 45 seconds. Diuretics and dietary protein were withdrawn and daily enemas, neomycin, aluminium hydroxide, cimetidine, intravenous dextrose and vitamins were instituted. However, jaundice deepened, asterixis appeared,

(C) The Fellowship of Postgraduate Medicine, 1988 
and 2 days later, he lapsed into deep coma and died.

Autopsy revealed massive hepatic necrosis with areas of fatty degeneration, but without evidence of regeneration or cirrhosis. The spleen showed evidence of chronic malaria. Paraffin embedded sections of the liver, stained with orcein ${ }^{12}$ were negative for $\mathrm{HbsAg}$ inclusion bodies. Serum collected at the onset of jaundice and frozen at $-20^{\circ} \mathrm{C}$ was later tested by radioimmunoassay at Northwick Park Hospital, Harrow, and found to be strongly positive for $\mathrm{HbsAg}$.

\section{Case 2}

A 60 year old teacher presented in October 1985 with nephrotic syndrome of 8 months duration, previously treated with diuretics, steroids, medicinal roots and herbs. Examination revealed anasarca, and a BP of $110 / 80 \mathrm{~mm} \mathrm{Hg}$. His haemogram was normal and thick blood films were negative for parasites. Blood urea was $12.2 \mathrm{mmol} / 1$ (normal 2.5-6.5), creatinine $305 \mu \mathrm{mol} / 1$ (normal 65-135), creatinine clearance $32 \mathrm{ml} / \mathrm{min}$, cholesterol $12.6 \mathrm{mmol} / \mathrm{l}$, serum total protein $4 \mathrm{~g} / \mathrm{dl}$, albumin $1.4 \mathrm{~g} / \mathrm{dl}$, globulin $2.6 \mathrm{~g} / \mathrm{dl}$ and 24 hour urine protein $3.4 \mathrm{~g}$. Serum electrolytes, blood sugar, bilirubin, AST, chest X-ray, electrocardiogram and barium studies were normal. HbsAg tested in a commercial laboratory by agar-gel diffusion, using horse antiserum (Wellcome), was reported as negative. An ultrasound scan showed large, unobstructed kidneys but the patient refused biopsy. He was given a trial of prednisolone $100 \mathrm{mg}$ alternate daily with $40 \mathrm{~g}$ protein $/ 2 \mathrm{~g}$ salt diet and frusemide. He diuresed, lost all oedema and was discharged but proteinuria persisted at $3+$ (Albustix) during follow-up.

One month after discharge, prednisolone was tapered while cyclophosphamide $150 \mathrm{mg}$ /day was commenced and given for 8 weeks. However, proteinuria remained, oedema returned and azotaemia worsened.

He was readmitted in January 1986, two weeks after cyclophosphamide withdrawal, with lassitude, anorexia, oedema, ascites and jaundice. Serum total bilirubin was now $92 \mu \mathrm{mol} / \mathrm{l}$, AST $1800 \mathrm{IU} / \mathrm{l}$ and prothrombin time was prolonged by 60 seconds. On his second day in hospital, jaundice deepened, asterixis was noted and he became irrational, aggressive and subsequently delirious. Diuretics were withheld and a liver failure regime instituted. There were no facilities for haemodialysis, and ascites precluded peritoneal dialysis due to appropriate fluids for circulatory support being unavailable. Hydrocortisone was given for 48 hours and ampicillin was introduced from day 5 when his BP was noted to be unrecordable. By day 7 , he was clinically improved, less jaundiced, alert and rational, but oedema was worse. The lucid interval lasted 2 weeks after which jaundice deepened, signs of encephalopathy returned and he lapsed into grade-IV coma and died.

Autopsy showed characteristic features of membranous glomerulonephritis and massive liver necrosis without evidence of regeneration. Examination of the liver sections stained with orcein did not show cytoplasmic inclusion bodies in any hepatocytes. Serum collected and frozen in early February and tested by radioimmunoassay in Harrow in July 1986 was positive for HbsAg.

\section{Discussion}

Fulminant hepatitis in these patients most likely resulted from $\mathrm{HBV}$ infection, or superinfection with another virus, as none of the drugs given is known to cause this complication. Although IgM antibody to hepatitis B core antigen was not measured, the presence of $\mathrm{HbsAg}$ in their sera points to $\mathrm{HBV}$ as the cause and the absence of orcein-positive (HbsAg-containing) hepatocytes at autopsy in either case would be consistent with fulminant acute hepatitis B rather than a coincidental HBV carrier state. ${ }^{12}$ A fulminant course with death results in 1 to $3 \%$ of cases of acute hepatitis $B^{13}$ and it is possible that these patients merely reflect the natural history of the disease. However, the temporal relationships suggest that fulminant hepatitis was precipitated by withdrawal of prednisolone (Case 1) or cyclophosphamide (Case 2).

Immunosuppression enhances HBV replication and widespread infection of hepatocytes. ${ }^{14}$ Its abrupt cessation permits a resurgence of cellmediated immunity with destruction of infected hepatocytes and elimination of the virus. This may result in transient hepatitis ${ }^{15}$ or liver failure ${ }^{14}$ in patients with chronic hepatitis B. However, acute fulminant hepatic failure has occurred in patients with malignant diseases ${ }^{8,10}$ and renal allograft. ${ }^{11}$ This paper presents the first reports of rebound hepatic necrosis in nephrotic syndrome following cessation of immunosuppression. In all the reported cases, hepatic failure occurred within 2 to 6 weeks of drug withdrawal, reflecting the variable time lapse required for complete drug clearance and for cytotoxic T-lymphocytes to recover full immune competence.

It is surprising that steroid withdrawal over two weeks in Case 1 was sufficiently abrupt to precipitate massive liver necrosis. Superimposed malnutrition in this patient may have facilitated saturation infection of hepatocytes and, 
consequently, total destruction of hepatic reserve. Furthermore, increased steroid bioavailability due to hypoalbuminaemia ${ }^{16}$ probably resulted in more profound immunosuppression and a greater rebound in immune stimulation (and liver cell damage) following steroid withdrawal.

The local HbsAg test result from Case 2 may have been a false negative because the agar-gel diffusion technique is relatively insensitive. ${ }^{17}$ The lucid interval observed in this patient probably resulted from hydrocortisone therapy given, only for $\mathbf{4 8}$ hours, for hypotension.

Hepatic failure following withdrawal of immunosuppression may not be uncommon in tropical Africa where $\mathrm{HBV}$ infection is highly prevalent ${ }^{6}$ and steroids are readily prescribed by practitioners often without $\mathrm{HbsAg}$ screening. Sadly, the unsuspecting clinician may not relate the event to the preceding immunosuppression. It is essential to screen all patients for HbsAg prior to the initiation of immunosuppressive drugs, and to avoid this form of therapy in positive cases. However, $\mathrm{HbsAg}$ screening is expensive, not widely available and may provide misleading information in these lowresource countries. In situations of uncertainty,

\section{References}

1. Brzosko, W.J., Krawcynski, K., Nazarewicz, T., Morzycka, M. \& Nowoslawski, A. Glomerulonephritis associated with hepatitis B surface antigen immune complexes in children. Lancet 1974, ii: 477.

2. Nagy, J., Bajtai, G., Brasch, H. et al. HbsAg in renal disease. Lancet 1978, ii: 315.

3. Obineche, E.N. \& Awunor-Renner, C. The role of hepatitis B surface antigen in acute glomerulonephritis in adults. East Afr Med J 1981, 58: 341.

4. Abdurrahman, M.B. Fakunle, Y.M. \& Whittle, H.C. The role of hepatitis B surface antigen in Nigerian children with nephrotic syndrome. Ann Trop Paediatr 1983, 3: 13.

5. Kibukamusoke, J.W., Hutt, M.S. \& Wilks, N.E. The nephrotic syndrome in Uganda and its association with quartan malaria. $Q J$ Med 1967, 36: 393.

6. Fakunle, Y.M., Abdurrahman, M.B. \& Whittle, H.C. Hepatitis B virus infection in children and adults in northern Nigeria: a preliminary survey. Trans $R$ Soc Trop Med Hyg 1981, 75: 626.

7. Taylor, R.D., Corcoran, A.C. \& Page, I.H. Treatment of the nephrotic syndrome with nitrogen mustard. $J$ Lab Clin Med 1950, 36: 996.

8. Galbraith, R.M., Eddleston, A.L.W.F., Williams, R., Zuckerman, A.J. \& Bagshawe, R.D. Fulminant hepatic failure in leukaemia and choriocarcinoma related to withdrawal of cytotoxic drug therapy. Lancet 1975, ii: 528 .

9. Wands, J.R. Subacute and chronic active hepatitis after withdrawal of chemotherapy. Lancet 1975, ii: 979. useful practical guidelines would be, first to withdraw immunosuppressive drugs gradually and, secondly, to monitor the patients closely during and after withdrawal. Since these two cases, we now taper cyclophosphamide (as for prednisolone) in patients whose $\mathrm{HbsAg}$ status has not been reliably determined. When the daily dose falls below the unit strength of the tablet, we adopt alternate daily, twice and once weekly pulsing to allow a more gradual recovery of immune competence. We monitor the patients for early detection of jaundice, bile in the urine, rising serum bilirubin or AST levels, or prolonged prothrombin time, and we promptly intervene with steroids at the first clinical or biochemical signs of hepatocellular damage.

\section{Acknowledgements}

I wish to thank Dr G. Ejeckam of the Pathology Department for expert assistance with renal biopsy interpretation and post mortem examination, Dr D. Seal and Dr R. Wall of the Microbiology Department of Northwick Park Hospital, Harrow for HBV serology and Professor W. Onuigbo for critical reading of the typescript.

10. Thung, S.N., Gerber, M.A., Klion, F. \& Gilbert, H. Massive hepatic necrosis after chemotherapy withdrawal in a hepatitis B virus carrier. Arch Int Med 1985, 145: 1313.

11. Hanson, C.A., Sutherland, D.E. \& Snover, D.C. Fulminant hepatic failure in an $\mathrm{HbsAg}$ carrier renal transplant patient following cessation of immunosuppressive therapy. Transplantation 1985, 39: 311.

12. Shikata, T., Uzawa, T., Yoshiwara, N., Akatsuka, T. \& Yamasaki, S. Staining methods of Australia antigen in paraffin section-detection of cytoplasmic inclusion bodies. Jpn J Exp Med 1974, 44: 25.

13. Sherlock, S. Acute and chronic viral hepatitis revisited. Australian NZ J Med 1985, 15: 88.

14. Nair, P.V., Tong, M.J., Stevenson, D., Roskamp, D. \& Boone, C. Effects of short-term high-dose prednisolone treatment of patients with $\mathrm{HbsAg}$ positive chronic active hepatitis. Liver 1985, 5: 8.

15. Hoofnagle, J.H., Davis, G.L., Pappas, S.C. et al. A short course of prednisolone in chronic type B hepatitis. Ann Int Med 1986, 104: 12.

16. Lewis, G.P., Jusko, W.J., Graves, L. et al. Prednisolone side-effects and serum protein levels. A collaborative study. Lancet 1971, ii: 778 .

17. Reesink, H.W., Lafeber-Schut, L.J., Aaij, C. et al. Comparison of six 'third generation' tests for the detection of HbsAg. Vox Sanguinis 1980, 39: 61. 